\title{
Indicators of Antarctic ozone depletion
}

\author{
G. E. Bodeker ${ }^{1}$, H. Shiona ${ }^{1}$, and H. Eskes ${ }^{2}$ \\ ${ }^{1}$ National Institute of Water and Atmospheric Research, Lauder, New Zealand \\ ${ }^{2}$ Koninklijk Nederlands Meteorologisch Instituut, De Bilt, The Netherlands
}

Received: 17 March 2005 - Published in Atmos. Chem. Phys. Discuss.: 8 June 2005

Revised: 1 September 2005 - Accepted: 12 September 2005 - Published: 29 September 2005

\begin{abstract}
An assimilated data base of total column ozone measurements from satellites has been used to generate a set of indicators describing attributes of the Antarctic ozone hole for the period 1979 to 2003, including (i) daily measures of the area over Antarctica where ozone levels are below $150 \mathrm{DU}$, below $220 \mathrm{DU}$, more than $30 \%$ below 1979 to 1981 norms, and more than $50 \%$ below 1979 to 1981 norms, (ii) the date of disappearance of $150 \mathrm{DU}$ ozone values, 220 DU ozone values, values 30\% below 1979 to 1981 norms, and values 50\% below 1979 to 1981 norms, for each year, (iii) daily minimum total column ozone values over Antarctica, and (iv) daily values of the ozone mass deficit based on a $\mathrm{O}_{3}<220 \mathrm{DU}$ threshold. The assimilated data base combines satellite-based ozone measurements from 4 Total Ozone Mapping Spectrometer (TOMS) instruments, 3 different retrievals from the Global Ozone Monitoring Experiment (GOME), and data from 4 Solar Backscatter UltraViolet (SBUV) instruments. Comparisons with the global ground-based Dobson spectrophotometer network are used to remove offsets and drifts between the different data sets to produce a global homogeneous data set that combines the advantages of good spatial coverage of satellite data with good long-term stability of ground-based measurements. One potential use of the derived indices is detection of the expected recovery of the Antarctic ozone hole. The suitability of the derived indicators to this task is discussed in the context of their variability and their susceptibility to saturation effects which makes them less responsive to decreasing stratospheric halogen loading. It is also shown that if the corrections required to match recent Earth Probe TOMS measurements to Dobson measurements are not applied, some of the indictors are affected so as to obscure detection of the recovery of the Antarctic ozone hole.
\end{abstract}

Correspondence to: G. E. Bodeker

(g.bodeker@niwa.co.nz)

\section{Introduction}

Over the next few decades, decreases in ozone depleting substances in the stratosphere are expected to lead to increases in ozone and eventual recovery of the Antarctic ozone hole (Austin et al., 2003). Ground-based measurements have confirmed that tropospheric chlorine concentrations have been decreasing since 1993 (Montzka et al., 1996) and more recently decreases in stratospheric chlorine concentrations have been observed (Rinsland et al., 2003). Detecting the resultant recovery of the Antarctic ozone layer can be aided by deriving a set of indices which capture the essential characteristics of the ozone hole. The nature of these indices, such as their long-term variability and their susceptibility to saturation effects, will determine their suitability for detecting recovery.

To this end, this paper first updates the NIWA assimilated total column ozone data base (Sect. 2) which has been used in a number of previous studies of global ozone variability (Bodeker et al., 2001a,b, 2002; Fioletov et al., 2002; WMO, 2003). As such, the paper documents in detail the construction of version 2 of the NIWA assimilated total column ozone data base. Using this global homogenized data base, a set of indicators which describe the Antarctic ozone hole are derived and investigated for their applicability to detection of Antarctic ozone hole recovery (Sect. 3). The conclusions of this analysis and an outline of directions for future use of these indices is presented in Sect. 4.

A number of previous studies have calculated indicators of Antarctic ozone depletion. Uchino et al. (1999) examined changes in the area of the Antarctic ozone hole using a threshold of $\mathrm{O}_{3}<220 \mathrm{DU}\left(1 \mathrm{DU}=2.69 \times 10^{16}\right.$ molecules $/ \mathrm{cm}^{2}$ ) as well the ozone mass deficiency within the ozone hole. Newman et al. (2004) investigated the past and expected future development of the size of the Antarctic ozone hole and investigated the sensitivity of this metric to changes in stratospheric halogen loading and temperatures. It was

(C) 2005 Author(s). This work is licensed under a Creative Commons License. 

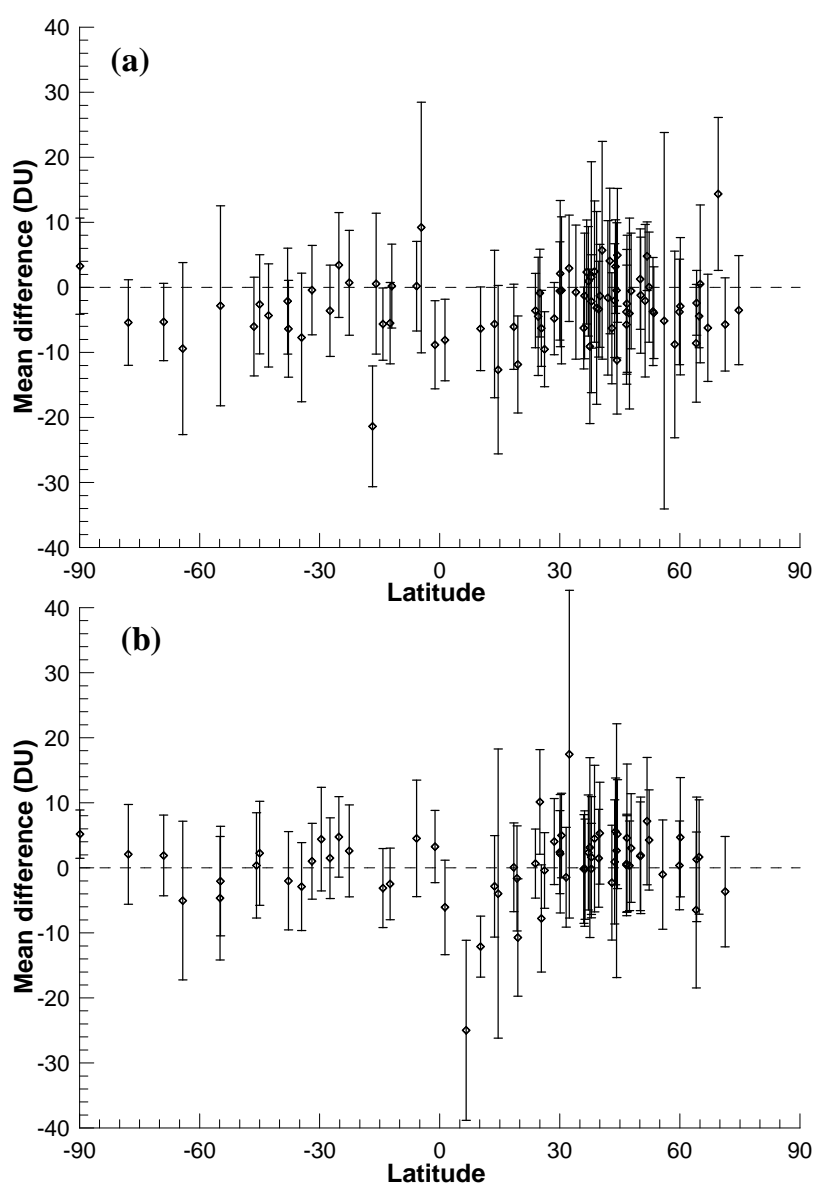

Fig. 1. Means (diamonds) and $1 \sigma$ standard deviations (error bars) of the Dobson minus TOMS differences at each Dobson spectrophotometer station; (a) Dobson-N7T differences (b) Dobson-EPT differences.

found that the size of the ozone hole using the threshold of $\mathrm{O}_{3}<220$ DU was rather insensitive to changes in effective equivalent stratospheric chlorine (EESC; Daniel et al., 1995) as discussed in greater detail in Sect. 3.2.

\section{Homogenization of the satellite data}

The data base used in this analysis is an update and extension of the homogenized total column ozone data set developed by Bodeker et al. (2001a) (hereafter referred to as B2001). Specific changes include:

- Version 8 Nimbus 7 and Earth Probe TOMS (Total Ozone Mapping Spectrometer) data are used rather than version 7 (http://toms.gsfc.nasa.gov/).

- GOME data from the European Space Agency (ESA) are updated from version 2.4 (used in B2001) to version 3.1 .

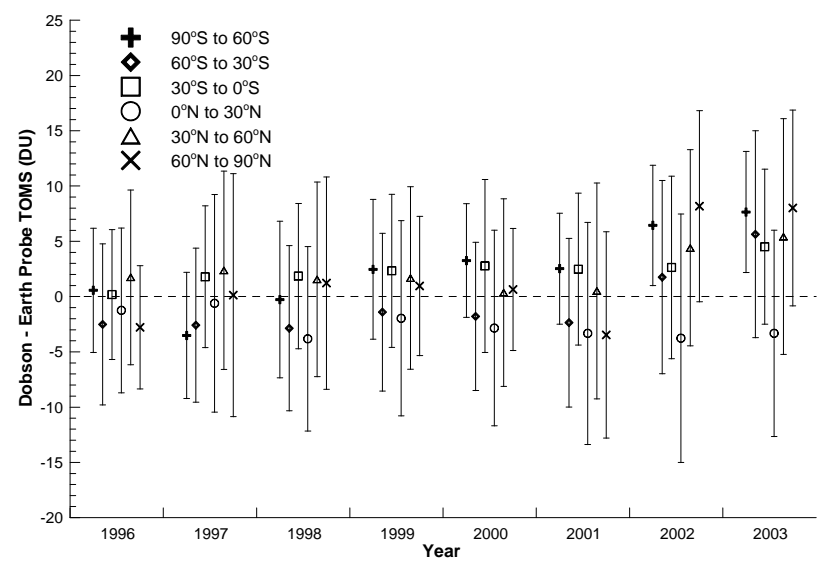

Fig. 2. Mean Dobson-EPT differences for each year and for a range of latitude zones (symbols) together with their $1 \sigma$ standard deviations.

- Assimilated total column ozone fields from KNMI (http://www.knmi.nl/goa) based on GOME measurements are included.

- KNMI TOGOMI total column ozone fields (http:// www.temis.nl/protocols/O3total.html) are included.

- Version 8 SBUV (Solar Backscatter Ultra-Violet) data from the NASA Nimbus 7, NOAA 9, NOAA 11 and NOAA 16 satellites (http://www.cpc.ncep.noaa. gov/products/stratosphere/sbuv2to/) are included.

and the analysis period is extended to the end of 2003 (B2001 analyses extended to the end of 1998). The updates to B2001 associated with each of these changes are detailed in Sects. 2.1 to 2.5 .

\subsection{Change from version 7 to version 8 TOMS ozone}

Recently the Nimbus 7 TOMS (N7T) and Earth Probe TOMS (EPT) measurements were reprocessed using version 8 of the retrieval algorithm. This algorithm implements a number of improvements over the earlier version 7 algorithm (McPeters et al., 1996). The total column ozone retrievals are improved for conditions such as high tropospheric aerosol loading, sun glint, persistent snow/ice, and very high solar zenith angles (Wellemeyer et al., 2004). Use of a vertical ozone profile climatology dependent on latitude and season reduces errors due to limited sensitivity of backscattered ultraviolet radiance to ozone in the lower troposphere. The algorithm also includes an improved cloud height database from the Nimbus 7 Temperature Humidity Infrared Radiometer (THIR) and a more accurate terrain height data base (Wellemeyer et al., 2004; Labow et al., 2004).

Three-hourly means of version 8 N7T and EPT overpass data and direct-sun only Dobson spectrophotometer measurements were calculated at all Dobson spectrophotometer 

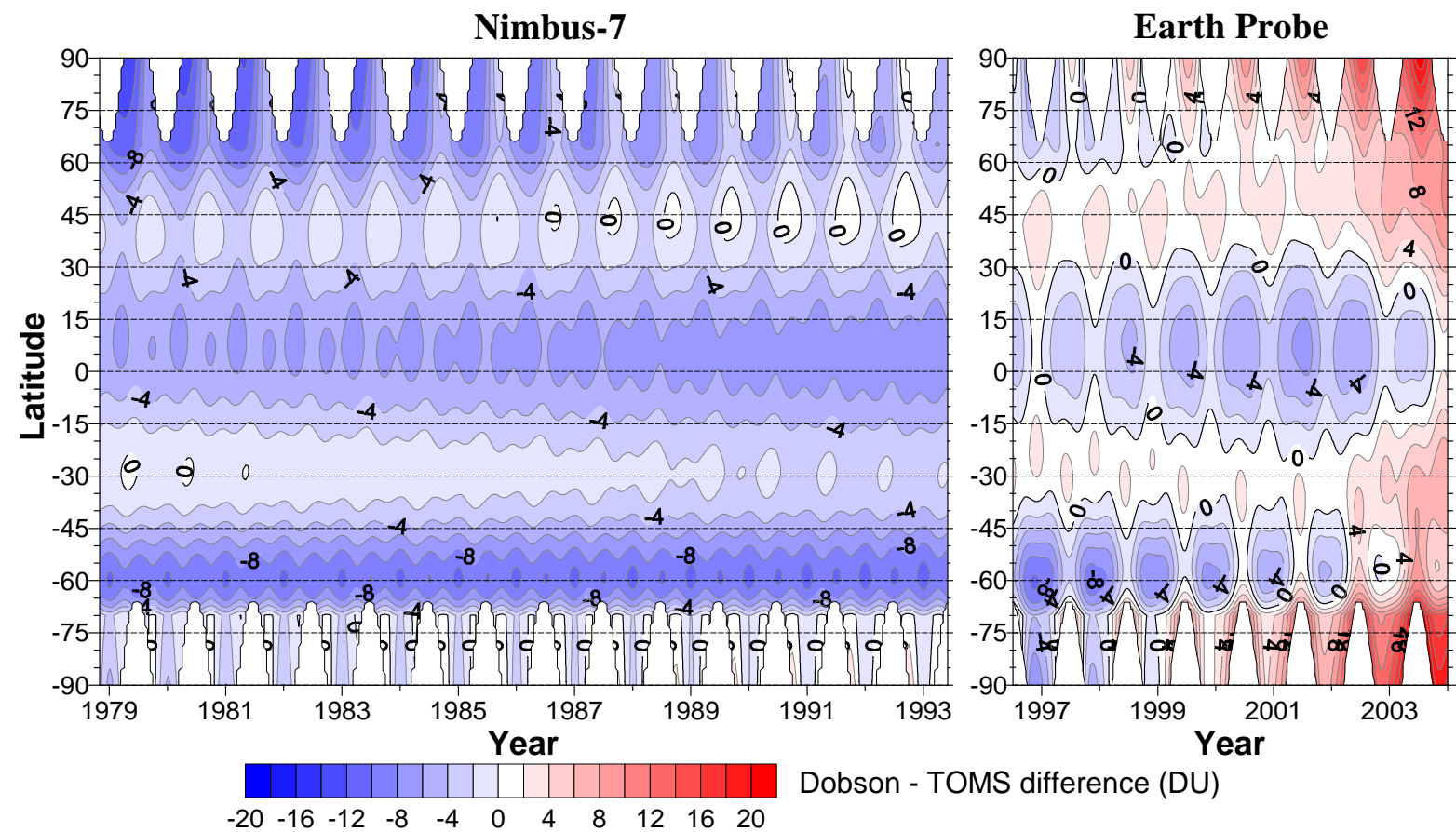

Dobson - TOMS difference (DU)

Fig. 3. The fit to the Dobson-N7T differences (Dobson minus TOMS) and the Dobson-EPT differences. Contour intervals are 2 DU. Regions with positive differences are shown in red (TOMS underestimates ozone) while regions with negative differences are shown in blue (TOMS overestimates ozone). Masked areas in winter high latitudes indicate where comparisons cannot be made since these regions are in polar night were no measurements can be made.

sites submitting data to the World Ozone and Ultraviolet Radiation Data Centre (WOUDC). The acceptance criteria for the Dobson measurements were tightened over those employed in B2001 so that only "AD wavelength, ordinary setting" (WlCode $=0)$ and direct sun $(\mathrm{ObsCode}=0)$ measurements were used. As a result, Longyear, Uccle, and Sofia were no longer used in the comparisons with N7T and Ny Alesund, Sofia, and Salto were no longer used in the comparisons with EPT (cf. Table 2 of B2001). Additional sites used in the EPT intercomparison were Moscow, Lisbon (also for N7T), and Ushuaia. An updated version of Fig. 1 of B2001 is shown in Fig. 1 here.

In comparison to the differences shown in B2001, the differences shown in Fig. 1 are significantly smaller showing a dramatic improvement in the version 8 TOMS data over the version 7 data when compared with Dobson spectrophotometer measurements. More recently, however, an anomaly in the EPT data has been discovered (McPeters, personal communication) evident as increasing differences between EPT and coincident Dobson measurements from 2002 onwards (Fig. 2).

To incorporate the increasing drift between the EPT and Dobson measurements in recent years, an additional linear trend term, set to zero before 2002, was added to the 22 parameter function fit to the Dobson-TOMS differences used in B2001. Such functions are fitted to the difference data sets to avoid the effects of local inhomogeneities in the Dobson time series, different temporal distribution of the Dobson data, and different geographical coverage of the Dobson data. The resultant function fits are shown in Fig. 3.

An increased trend in the Dobson-EPT differences beyond 2002 is clear in the right hand panel of Fig. 3. The additional trend in the differences beyond 2002 is 3.33 DU/year. Before 2002, and over the majority of the globe, the differences between the version 8 N7T and EPT data and measurements from the global Dobson spectrophotometer network are less than $10 \mathrm{DU}$ and show little or no drift. As in B2001, the function fits plotted in Fig. 3 were applied as corrections to the N7T and EPT data, though in this case the corrections applied are much smaller than the corrections applied to the version 7 data.

To correct for any potential offset and drift between the corrected version 8 TOMS data and the version 7 Meteor 3 TOMS (M3T) and Adeos TOMS (ADT) data, daily $2^{\circ}$ zonal means for each data set were calculated and differenced during their period of overlap (for M3T: 22 August 1991 to 6 May 1993; for ADT: 11 September 1996 to 29 June 1997). For the calculation of the zonal means, and for those of the other data sets presented below, there had to be at least two measurements within each of six $60^{\circ}$ longitudinal sectors. Because corrections to the version 7 data may need to be applied to periods beyond the period of overlap with the version 


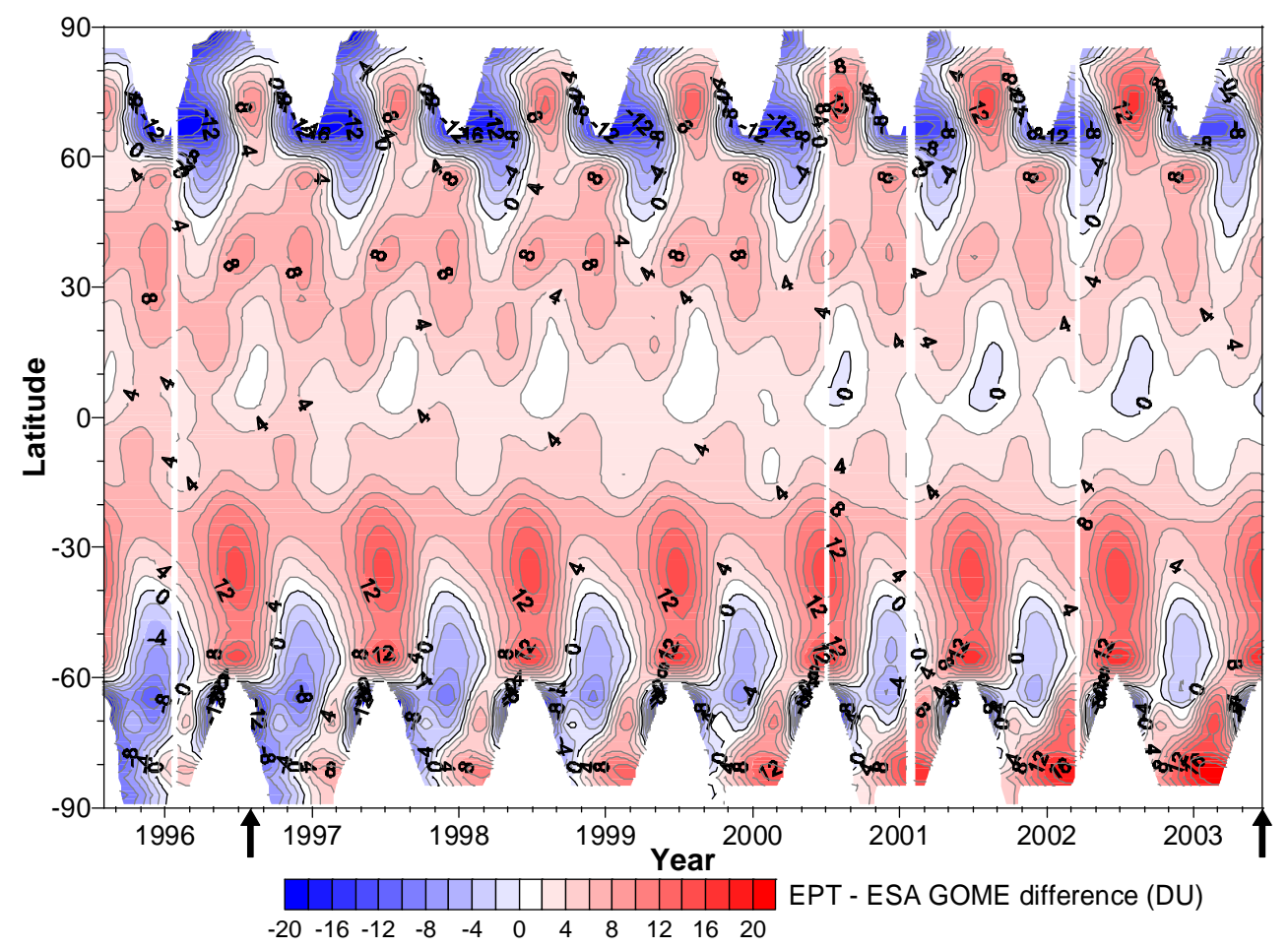

Fig. 4. The fits to the differences between the version 8 EPT zonal means and the ESA GOME zonal means. Contour spacing is 2 DU with the 0 DU contour shown in bold. Regions with positive differences are shown in red (ESA GOME underestimates ozone) while regions with negative differences are shown in blue (ESA GOME overestimates ozone). The arrows on the X axis show the start and end of the period over which the fits were calculated.

8 data (e.g. corrections to M3T beyond 6 May 1993), functions of the form

$$
\begin{aligned}
\Delta(\phi, t) & =A+B \times t+C \times \sin (2 \pi t)+D \times \cos (2 \pi t) \\
& +E \times \sin (4 \pi t)+F \times \cos (4 \pi t) .
\end{aligned}
$$

where $\Delta$ is the difference between coincident N7T and M3T or EPT and ADT measurements, and $t$ is the time in decimal years, were fitted to the difference time series in each $2^{\circ}$ zone. At latitudes above $75^{\circ}$ the semi-annual component is not fitted since there is seldom enough data to constrain the fit (as a result of lack of TOMS measurements during polar night). The fits to the differences for M3T and ADT are not shown here but are essentially similar to those reported in B2001.

\subsection{Update of ESA GOME data from version 2.4 to 3.1}

B2001 used the version 2.4 operational GOME ozone product from ESA, whereas this study has used updated version 3.1 data. The data are currently available from August 1995 to May 2003. On 22 June 2003 a tape recorder failure on the ERS 2 satellite resulted in only a small portion of the Northern Hemisphere being sampled by the GOME instrument thereafter. The fits to the differences between the corrected zonal mean EPT data and the ESA GOME data (Eq. 1) are shown in Fig. 4.
Except for the winter-time over southern midlatitudes and winter-time over northern high latitudes, differences are most often less than $10 \mathrm{DU}$. These difference fits were then used to correct all ESA GOME data.

\subsection{KNMI GOME assimilated ozone}

A detailed description of the KNMI assimilated GOME product (hereafter referred to as GOA) is provided in Eskes et al. (2003). The assimilation is based on the version $3 \mathrm{GOME}$ data processor discussed in the previous section. Synoptic global total column ozone fields are provided every $6 \mathrm{~h}$ at $1.5^{\circ}$ resolution in longitude by $1.0^{\circ}$ resolution in latitude. As for the ESA GOME product, data are currently available from August 1995 to May 2003. A similar approached to that used to derive corrections to the ESA GOME data was used to derive corrections for the GOA data. The resultant fit of Eq. (1) to the EPT-GOA differences is shown in Fig. 5.

Differences are generally less than $10 \mathrm{DU}$. When comparing Fig. 4 and Fig. 5 it should be kept in mind that since the assimilation is built on an atmospheric transport model, biases in ozone over e.g. middle to high latitudes can be transported to lower latitudes. Furthermore any shortcomings in the transport model such as inadequate representation of the subtropical barrier to transport will be reflected in ozone biases. Finally, any changes in the meteorological reanalyses 


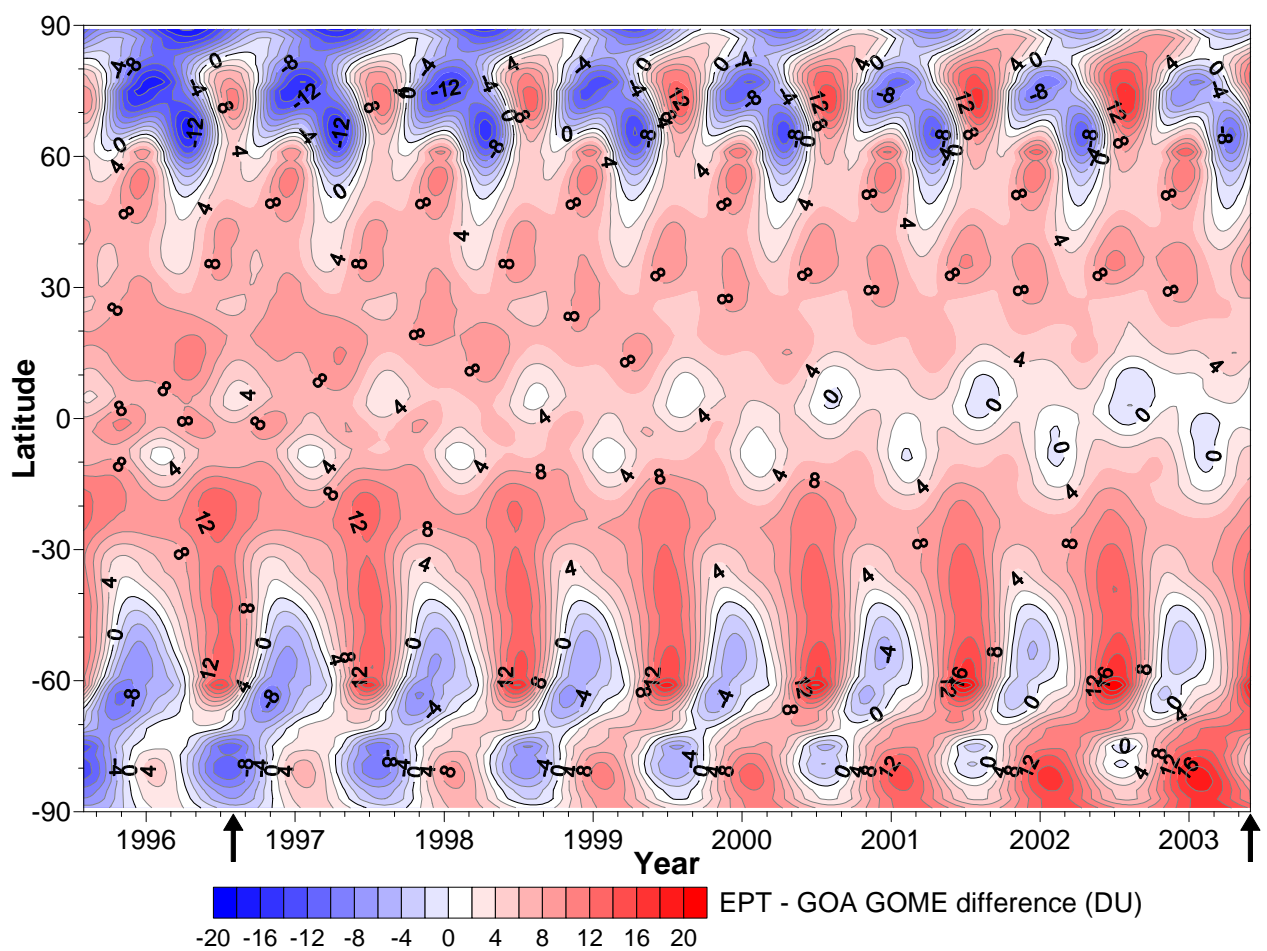

Fig. 5. The fits to the differences between the corrected version 8 EPT zonal means and the GOA GOME zonal means. Contour spacing is 2 DU with the 0 DU contour shown in bold. Regions with positive differences are shown in red (GOA GOME underestimates ozone) while regions with negative differences are shown in blue (GOA GOME overestimates ozone). The arrows on the X axis show the start and end of the period over which the fits were calculated.

used to drive the model (for the GOA assimilation a change was made from ERA-40 to operational ECMWF analyses in November 1999) may also affect the ozone fields.

\subsection{KNMI TOGOMI ozone}

A new algorithm for total column ozone retrieval from the GOME instrument has been developed (Valks and van Oss, 2003). This algorithm, named TOGOMI (Total Ozone algorithm for GOME using the OMI algorithm), is based on the total ozone Differential Optical Absorption Spectroscopy (DOAS) algorithm developed for the OMI instrument (Veefkind and de Haan , 2001). It resolves various limitations of the current operational GOME algorithm (GDP v3) used to generate the ESA GOME data used in this study (Sect. 2.2). A description of some of these limitations was provided in B2001. The main improvements of the new algorithm are:

1. New treatment of rotational Raman scattering in the DOAS algorithm. The new formulation explicitly accounts for smearing of solar Fraunhofer lines as well as atmospheric tracer absorption structures,

2. Improvements in the calculation of the air mass factor using the so-called empirical approach,
3. A-priori profiles required in the retrieval are taken from the improved ozone profile climatology used in the version 8 TOMS algorithm (Labow et al., 2004),

4. Using the Fast Retrieval Scheme for Clouds from the Oxygen A-band (FRESCO) algorithm for the cloud correction,

5. Treatment of the atmospheric temperature sensitivity using effective ozone cross-sections calculated from ECMWF temperature profiles,

6. Accurate semi-spherical polarization-dependent radiative transfer calculation (KNMI DAK model).

Global total column ozone data fields retrieved using the TOGOMI algorithm are available from 13 March 1996 to 11 August 2003, although for reasons outlined above, only limited data are available from 22 June 2003 onward. The results of the fits of Eq. (1) to differences between TOGOMI and corrected version 8 EPT total column ozone are shown in Fig. 6.

Over most of the globe between $60^{\circ} \mathrm{N}$ and $60^{\circ} \mathrm{S}$, the differences are less than $10 \mathrm{DU}$. Differences become larger close to polar night i.e. when the SZA becomes large. 


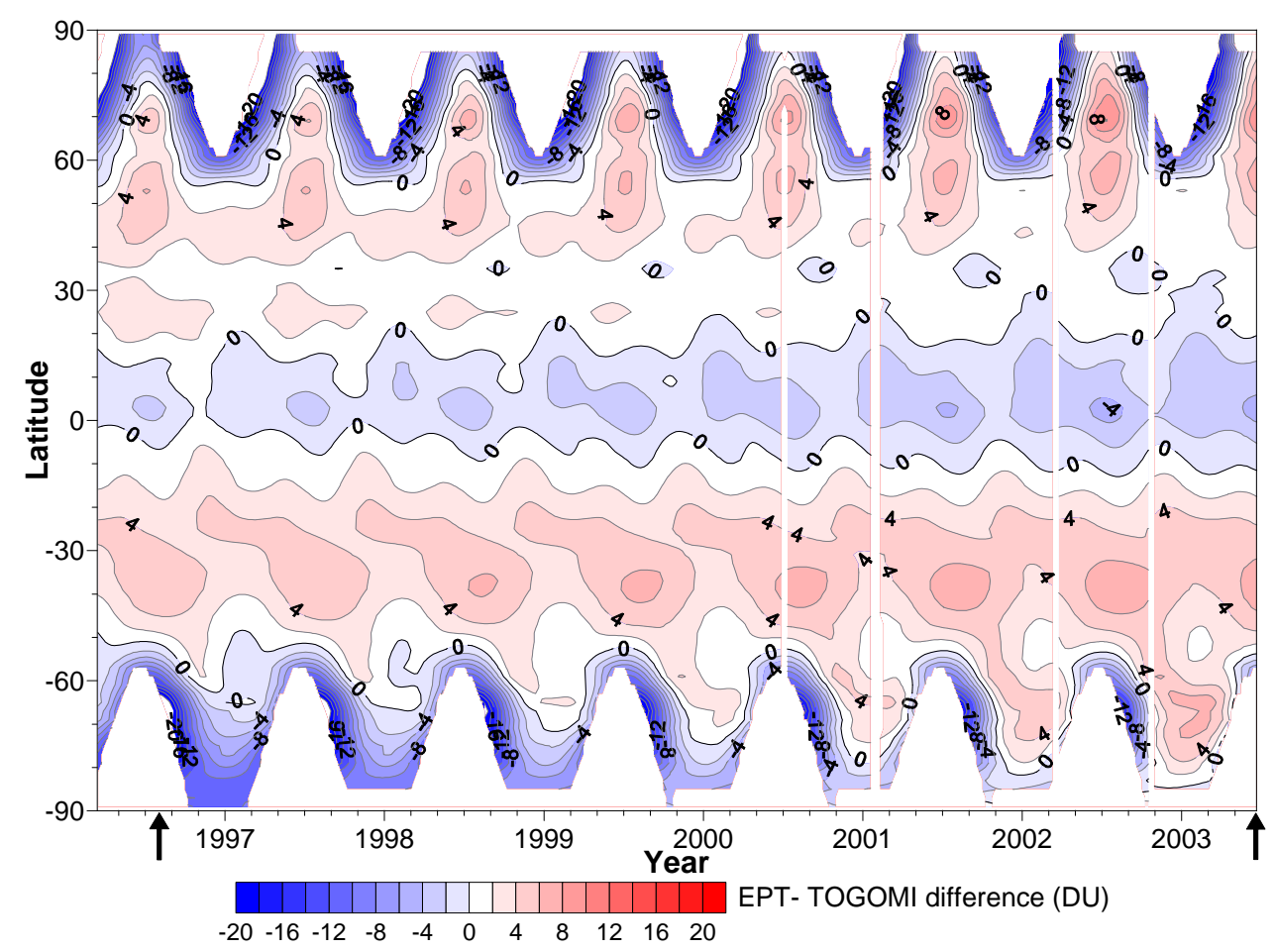

Fig. 6. The fits to the differences between the corrected version 8 EPT zonal means and the TOGOMI GOME zonal means. Contour spacing is $2 \mathrm{DU}$ with the $0 \mathrm{DU}$ contour shown in bold. Regions with positive differences are shown in red (TOGOMI underestimates ozone) while regions with negative differences are shown in blue (TOGOMI overestimates ozone). The arrows on the $\mathrm{X}$ axis show the start and end of the period over which the fits were calculated.

\subsection{SBUV ozone}

The four different SBUV data sets used in this analysis are summarized in Table 1.

Data quality control criteria applied to the SBUV total column ozone data included having at least 100 measurements within a hemisphere for the hemisphere of data to be considered valid (see Sect. 3.1 for the process used to fill missing data), data from both ascending and descending orbits were used but with the criterion of SZA $<84^{\circ}$ and the data having a maximum residual quality control parameter (ResQC) of 0.2 . Data were included where the data quality control flags in the SBUV data files were $0,10,100$ or 110 . This selection was made to maximize data availability without inclusion of poor quality data. In some cases this resulted in shorter time periods of data being available than those listed in Table 1.

A statistical summary of the differences between the $2^{\circ}$ zonal means of the 4 SBUV data sets and the corrected version 8 TOMS data (Nimbus 7 and Earth Probe) is presented in Table 1. The 'Num' column shows the number of intercomparison pairs used to generate the statistics shown in the other columns. For the SBUV instruments on NOAA 9 and NOAA 11, the mean differences are not statistically significantly different from zero (at the $1 \sigma$ level). Differences between the corrected TOMS and Nimbus 7/NOAA 16 SBUV data are somewhat larger. As an example, the function fits (Eq. 1) to the EPT - NOAA 16 SBUV differences are shown in Fig. 7.

Function fits similar to those shown in Fig. 7, derived for all four SBUV data sets, were then used to correct the SBUV data before they were used in the analyses presented below.

\section{Antarctic ozone depletion indices}

\subsection{Data selection and missing data}

The 11 data sets described above are corrected using their relevant correction functions and then combined to form a single homogeneous data set spanning the period November 1978 to December 2003. For each day, a single source of data is selected with the order of priority being (highest to lowest): Nimbus 7 TOMS, Earth Probe TOMS, Meteor 3 TOMS, Adeos TOMS, GOA GOME, TOGOMI GOME, ESA GOME, Nimbus 7 SBUV, NOAA 9 SBUV, NOAA 11 SBUV and finally NOAA 16 SBUV. It was felt that the superior spatial coverage and small TOMS-GOA differences made the GOA data preferable to the two other GOME data sets. The sparsity of the SBUV measurements places them at lowest priority. 
Table 1. The SBUV data used in this study together with a summary of TOMS (corrected N7T and EPT) - SBUV differences (TOMS minus SBUV). Difference values are in DU.

\begin{tabular}{crrrrrrrrr}
\hline Satellite platform & Start date & End date & Num & Mean & Stdv & Max & Min & 1st quartile & 3rd quartile \\
\hline Nimbus 7 (N7S) & $31 / 10 / 1978$ & $21 / 06 / 1990$ & 152504 & -4.763 & 3.998 & 30.39 & -40.65 & -6.68 & -2.39 \\
NOAA 9 (N9S) & $02 / 02 / 1985$ & $19 / 02 / 1998$ & 120592 & -3.131 & 4.832 & 37.56 & -56.54 & -5.79 & -0.74 \\
NOAA 11 (N11S) & $01 / 12 / 1988$ & $26 / 03 / 2001$ & 140394 & -3.303 & 4.355 & 49.71 & -69.43 & -5.59 & -0.82 \\
NOAA 16 (N16S) & $03 / 10 / 2000$ & $31 / 12 / 2003$ & 68243 & -5.351 & 5.039 & 29.29 & -41.84 & -8.36 & -2.50 \\
\hline
\end{tabular}

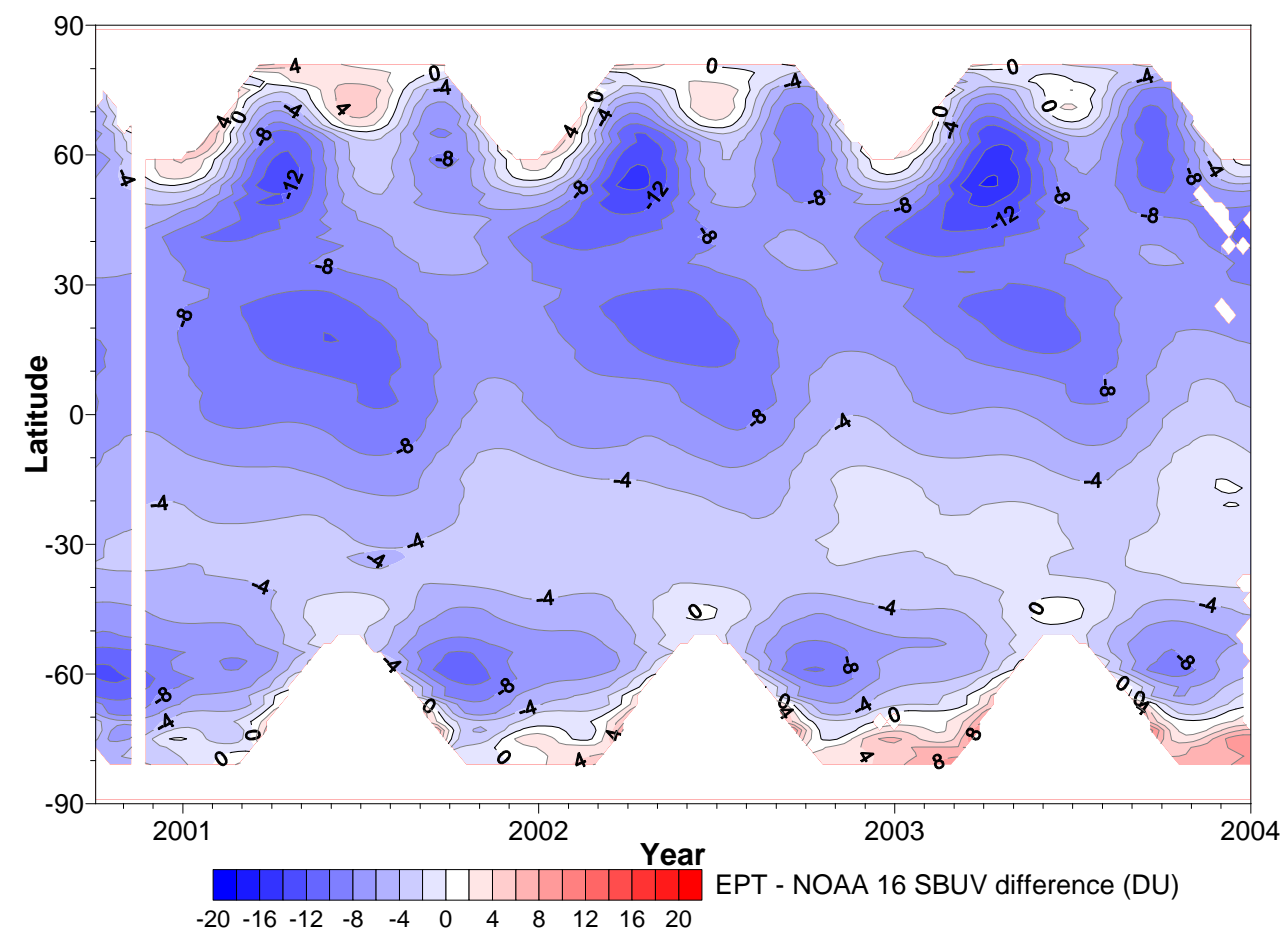

Fig. 7. The fits to the differences between the version 8 EPT zonal means and the NOAA 16 SBUV zonal means. Contour spacing is 2 DU with the 0 DU contour shown in bold. Regions with positive differences are shown in red (SBUV underestimates ozone) while regions with negative differences are shown in blue (SBUV overestimates ozone).

For many of the indices presented below, total column ozone values within the region of polar night need to be estimated. In this study the 'over the pole' linear interpolation method described and validated in Bodeker et al. (2001b) was used with the following constraints: interpolation in the zonal direction was not performed over more than $60^{\circ}$, interpolation in the meridional direction was not performed over more than $10^{\circ}$ (this constraint was relaxed poleward of $60^{\circ} \mathrm{S}$ to allow linear interpolation over the polar cap), and following the interpolation within these constraints there had to be no missing data poleward of $40^{\circ} \mathrm{S}$. If any of these constraints could not be met, the data set for that day was rejected.
The relative priority of the Earth Probe TOMS and GOA GOME data sets is debatable. While the GOA GOME data provide coverage during the polar night and therefore require no interpolation of missing data, they are essentially model output and may be influenced by shortcomings in the underlying transport model (Sect. 2.3). Then again, the ozone column forecast uncertainty generated along with the GOA GOME data could be used to screen for values that are "far away" from the measurements being assimilated. To test whether such a change in priority would affect the results, a second analysis was performed with the GOA GOME data placed higher in priority than the Earth Probe TOMS data. Where these results differ from those presented below, the differences are discussed.

In this analysis, only southern hemisphere ozone fields are used. The number of days of data used from each of the 11 data sets for each year is listed in Table 2. 
Table 2. A summary of the data used in this study. The first value shows the number of days of data in the given year from a particular data source. The values in parentheses show the number of days of data from each data source just for the Antarctic Vortex Period (AVP; day 200 to day 335 of each year). Note that in this analysis, no data from ADT, TOGOMI GOME or ESA GOME were used.

\begin{tabular}{cccccccccc}
\hline Year & N7T & M3T & EPT & GOA & N7S & N9S & N11S & N16S & Total \\
\hline 1979 & $309(127)$ & $0(0)$ & $0(0)$ & $0(0)$ & $7(1)$ & $0(0)$ & $0(0)$ & $0(0)$ & $316(128)$ \\
1980 & $358(133)$ & $0(0)$ & $0(0)$ & $0(0)$ & $3(1)$ & $0(0)$ & $0(0)$ & $0(0)$ & $361(134)$ \\
1981 & $361(135)$ & $0(0)$ & $0(0)$ & $0(0)$ & $1(1)$ & $0(0)$ & $0(0)$ & $0(0)$ & $362(136)$ \\
1982 & $363(136)$ & $0(0)$ & $0(0)$ & $0(0)$ & $2(0)$ & $0(0)$ & $0(0)$ & $0(0)$ & $365(136)$ \\
1983 & $363(136)$ & $0(0)$ & $0(0)$ & $0(0)$ & $1(0)$ & $0(0)$ & $0(0)$ & $0(0)$ & $364(136)$ \\
1984 & $364(134)$ & $0(0)$ & $0(0)$ & $0(0)$ & $2(2)$ & $0(0)$ & $0(0)$ & $0(0)$ & $366(136)$ \\
1985 & $364(136)$ & $0(0)$ & $0(0)$ & $0(0)$ & $1(0)$ & $0(0)$ & $0(0)$ & $0(0)$ & $365(136)$ \\
1986 & $361(136)$ & $0(0)$ & $0(0)$ & $0(0)$ & $1(0)$ & $2(0)$ & $0(0)$ & $0(0)$ & $364(136)$ \\
1987 & $365(136)$ & $0(0)$ & $0(0)$ & $0(0)$ & $0(0)$ & $0(0)$ & $0(0)$ & $0(0)$ & $365(136)$ \\
1988 & $366(136)$ & $0(0)$ & $0(0)$ & $0(0)$ & $0(0)$ & $0(0)$ & $0(0)$ & $0(0)$ & $366(136)$ \\
1989 & $364(136)$ & $0(0)$ & $0(0)$ & $0(0)$ & $1(0)$ & $0(0)$ & $0(0)$ & $0(0)$ & $365(136)$ \\
1990 & $365(136)$ & $0(0)$ & $0(0)$ & $0(0)$ & $0(0)$ & $0(0)$ & $0(0)$ & $0(0)$ & $365(136)$ \\
1991 & $364(136)$ & $0(0)$ & $0(0)$ & $0(0)$ & $0(0)$ & $0(0)$ & $1(0)$ & $0(0)$ & $365(136)$ \\
1992 & $366(136)$ & $0(0)$ & $0(0)$ & $0(0)$ & $0(0)$ & $0(0)$ & $0(0)$ & $0(0)$ & $366(136)$ \\
1993 & $126(0)$ & $159(101)$ & $0(0)$ & $0(0)$ & $0(0)$ & $33(33)$ & $2(2)$ & $0(0)$ & $320(136)$ \\
1994 & $0(0)$ & $211(88)$ & $0(0)$ & $0(0)$ & $0(0)$ & $120(45)$ & $4(1)$ & $0(0)$ & $335(134)$ \\
1995 & $0(0)$ & $0(0)$ & $0(0)$ & $153(123)$ & $0(0)$ & $131(9)$ & $10(0)$ & $0(0)$ & $294(132)$ \\
1996 & $0(0)$ & $0(0)$ & $160(129)$ & $206(7)$ & $0(0)$ & $0(0)$ & $0(0)$ & $0(0)$ & $366(136)$ \\
1997 & $0(0)$ & $0(0)$ & $352(132)$ & $13(4)$ & $0(0)$ & $0(0)$ & $0(0)$ & $0(0)$ & $365(136)$ \\
1998 & $0(0)$ & $0(0)$ & $344(134)$ & $21(2)$ & $0(0)$ & $0(0)$ & $0(0)$ & $0(0)$ & $365(136)$ \\
1999 & $0(0)$ & $0(0)$ & $361(134)$ & $4(2)$ & $0(0)$ & $0(0)$ & $0(0)$ & $0(0)$ & $365(136)$ \\
2000 & $0(0)$ & $0(0)$ & $366(136)$ & $0(0)$ & $0(0)$ & $0(0)$ & $0(0)$ & $0(0)$ & $366(136)$ \\
2001 & $0(0)$ & $0(0)$ & $363(134)$ & $2(2)$ & $0(0)$ & $0(0)$ & $0(0)$ & $0(0)$ & $365(136)$ \\
2002 & $0(0)$ & $0(0)$ & $353(124)$ & $12(12)$ & $0(0)$ & $0(0)$ & $0(0)$ & $0(0)$ & $365(136)$ \\
2003 & $0(0)$ & $0(0)$ & $350(132)$ & $9(0)$ & $0(0)$ & $0(0)$ & $0(0)$ & $6(4)$ & $365(136)$ \\
\hline
\end{tabular}

For the calculation of indices over the Antarctic Vortex Period (AVP; day 200 to day 335), missing values were filled by linear interpolation (interpolated values were zero or close to zero).

\subsection{Antarctic ozone hole area}

Daily measures of the area of the Antarctic ozone hole are shown in Fig. 8.

The very weak ozone hole during 2002 is clear, showing dramatic reductions in area in late September. For the threshold of $\mathrm{O}_{3} 50 \%$ below the 1979-1981 mean, there is a local minimum in the climatology and in the 2001 time series around the second week of November. This may result from the 1979-1981 baseline against which the comparisons are made having atypical seasonal variations during November (although the feature persisted if the climatology was extended to 1983). Except for 2001, ozone hole areas during the month of November are close to or lower than the mean values over 1979-1999 suggesting that ozone hole area during November may be a candidate indicator for Antarctic ozone hole recovery as also observed by Alvarez-Madrigal et al. (2005). This is shown more clearly in Fig. 9 where the
November means of the Antarctic ozone hole area are plotted for each year and for each threshold.

Recent November average ozone hole areas are more similar to those in the late 1980s or early 1990s. Whether or not the decreases in November average hole areas in the last four years is statistically significant (e.g. applying the methodology of Reinsel et al. (2002)) is beyond the scope of this paper. Note also the change in periodicity from $\sim 2$ year periodicity up to 1988,3 year periodicity from 1988 to 2000 , and then 2 year periodicity following 2000 .

Annual maximum ozone hole areas, and the dates on which they occur, are shown for all four threshold conditions in Fig. 10.

The maximum ozone hole area increases steadily over the 25 year period showing slightly higher values that those derived by Uchino et al. (1999) as a result of the negative offset corrections applied to the satellite-based measurements. If the data from the anomalous Antarctic ozone hole in 2002 are ignored, there is little or no indication of a reduction in the size of the ozone hole using the thresholds of $\mathrm{O}_{3}<220 \mathrm{DU}, \mathrm{O}_{3}<150 \mathrm{DU}$ or $\mathrm{O}_{3} 30 \%$ below the 1979-1981 mean, in agreement with previous studies (Newman et al., 2004). There is some indication however that the area of the 


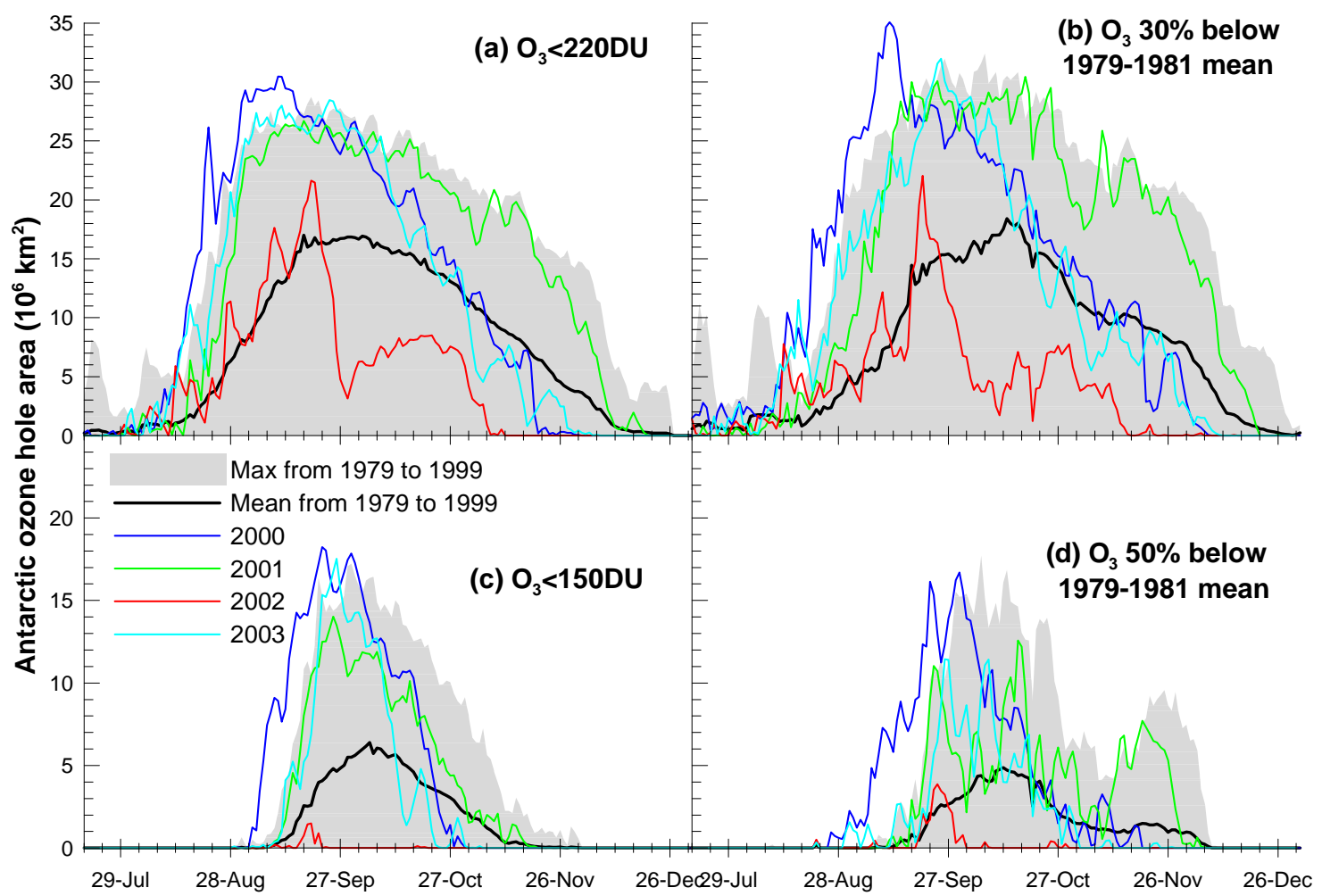

Fig. 8. Daily measures of the size of the Antarctic ozone hole using four different criteria. Values for 2000 (blue), 2001 (green), 2002 (red) and 2003 (cyan) are compared against the range of values over the period 1979-1999 (greyed area). The mean ozone hole area over the period 1979 to 1999 is shown using a thick black line in all 4 panels.

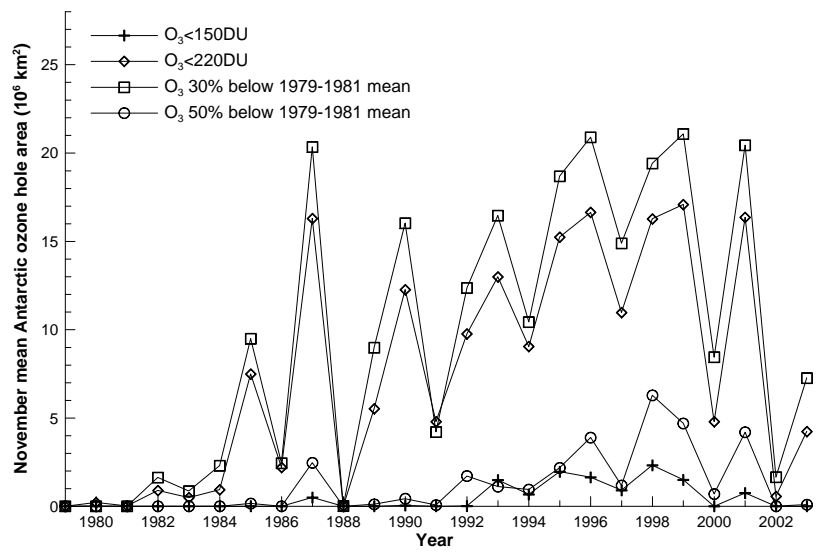

Fig. 9. November means of the Antarctic ozone hole area for the four different threshold conditions.

ozone hole with ozone 50\% below the 1979-1981 mean has decreased; over the 5 year period from 1999 to 2003, except for one year (2000), the area for every year has been below the minimum value over the 5 year period from 1994 to 1998 . There is an indication in the bottom panel of Fig. 10 that the date when the maximum occurs has shifted earlier over

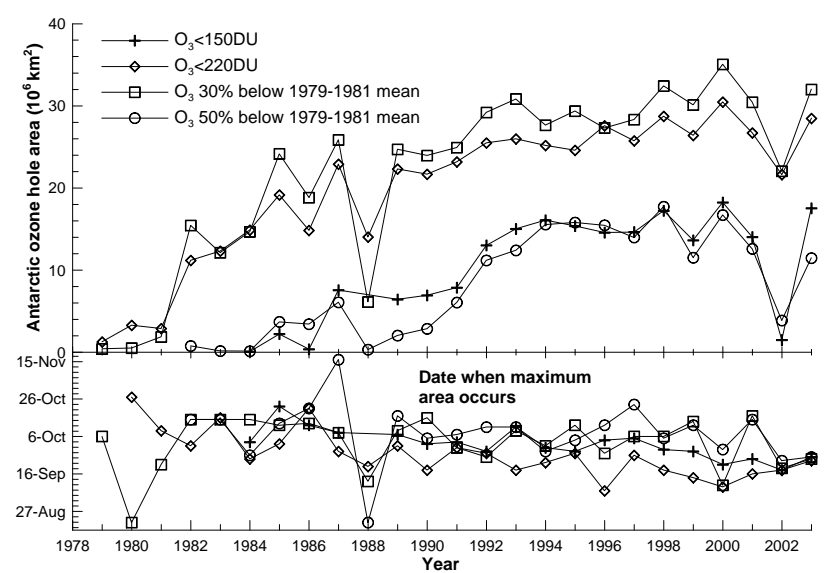

Fig. 10. The annual maximum ozone hole area for the four different threshold conditions, and the dates on which those maxima were achieved.

the period. For the $\mathrm{O}_{3}<220 \mathrm{DU}$ threshold condition, over the period 1980 to 2000 , the date on which the maximum ozone hole area occurs shifts earlier by more than 2 weeks per decade. For this threshold condition, over the most recent 4 years, the maximum area date drifts later by $\sim 18$ days. 


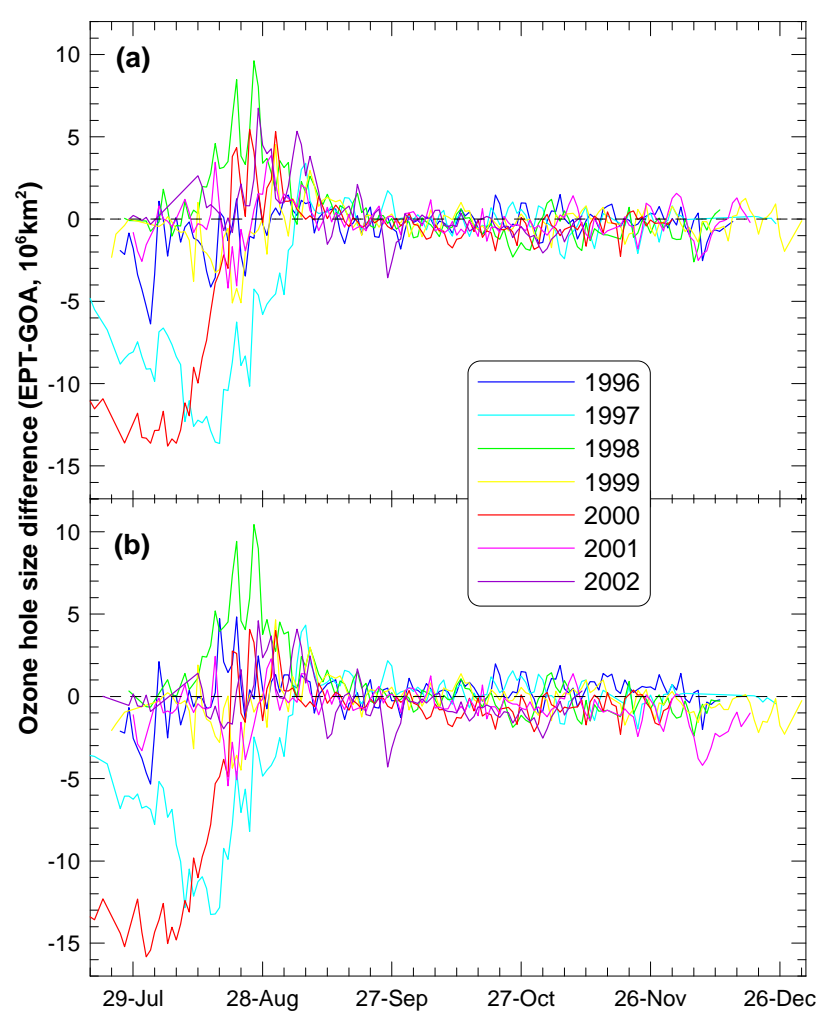

Fig. 11. Differences in the size of the Antarctic ozone hole calculated using the Earth Probe TOMS and GOA GOME data sets (EPTGOA) for (a) corrected EPT and GOA data, (b) corrected EPT and uncorrected GOA data.

Again, whether or not this is a sign of statistically significant ozone recovery is beyond the scope of the paper.

Early in the season there are differences in the size of the ozone hole calculated using the Earth Probe TOMS and GOA GOME data sets (Fig. 11).

However, because negative corrections were applied to the GOA GOME data over high southern latitudes during winter (Fig. 5) this may result in excessively large ozone hole values. Therefore a comparison of ozone hole areas from the corrected Earth Probe TOMS and uncorrected GOA GOME data sets is also shown in Fig. 11. Except for 1997, 1998 and 2000, the differences are generally less than 5 million $\mathrm{km}^{2}$ and after the first week of September are generally less than 2 million $\mathrm{km}^{2}$. The sources of these discrepancies are currently unknown but most likely relate to how the GOA assimilation model uses measurements close to the vortex edge (which may be in sunlight and therefore subject to ozone depletion chemistry) to infer ozone values deep within the vortex. In any event, the differences do not affect the results shown in Fig. 9 and Fig. 10.

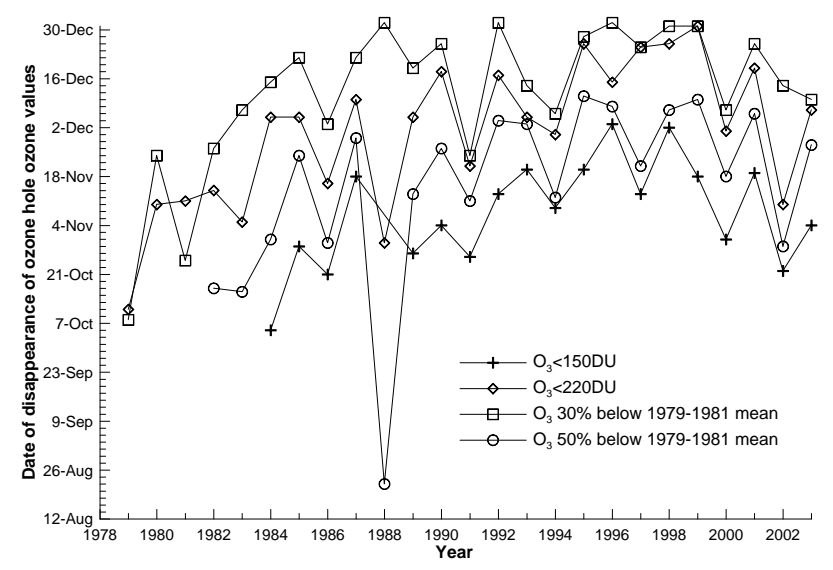

Fig. 12. The annual dates of disappearance of ozone hole type values for all four threshold criteria. In 1988 there were no ozone values below $150 \mathrm{DU}$.

\subsection{Date of ozone hole disappearance}

The annual dates of disappearance of ozone levels flagged as ozone hole values (latitude $\geq 40^{\circ} \mathrm{S}$ ) for all four threshold criteria are shown in Fig. 12.

The dates of disappearance of ozone hole values drift later into the year up until 1998/1999. Thereafter the date has shifted earlier in the year for all four threshold criteria. To investigate whether the recent earlier dates of disappearance of vortex like values are related to changes in the timing of the breakdown of the dynamical vortex, meridional impermiability, $\kappa$, on the $450 \mathrm{~K}$ surface was calculated for each day of each year (Bodeker et al., 2002). The date on which the meridional maximum $\kappa$ value falls below $10 \%$ of its annual maximum value was used to denote the dissipation of the dynamical vortex. Previous analyses have shown that from the late 1970s to the late 1990s the date of breakdown of the dynamical vortex has drifted later in the year by between 2 and 4 weeks, depending on the metric used to detect vortex breakdown (Uchino et al., 1999; Waugh et al., 1999). In 2000 and 2002 the dynamical vortex dissipated on the 19 and 18 November respectively (not shown graphically here). This was earlier than any previous vortex breakdown since 1979 when the vortex also dissipated on 18 November. In 2001, although the vortex dissipated on 14 December, 1 day later than in 1999, ozone hole like values disappeared 12 days earlier in 2001 than in 1999 suggesting that mechanisms other than changes in dynamics may also be driving earlier disappearance of ozone levels typical of the Antarctic ozone hole. In 2003 the dynamical vortex dissipated on 30 November which is also relatively early compared to the 1990s where in only two years (27 November 1991; 30 November 1997) did the vortex dissipate in November.

Earlier dates of dissipation of the dynamical vortex, and earlier dates of disappearance of ozone hole ozone values, 


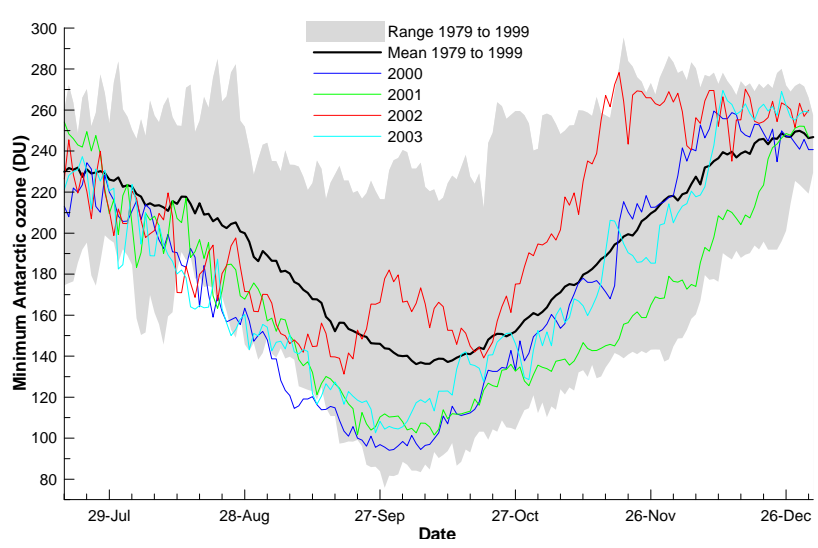

Fig. 13. Minimum Antarctic ozone levels for 2000 (blue), 2001 (green), 2002 (red) and 2003 (cyan) compared against the 19791999 climatology (range shown in grey and mean shown with thick black line).

have important implications for summer-time UV levels over southern midlatitudes (McKenzie et al., 1999). The closer the date of dissipation of the vortex to the summer solstice, the greater the likelihood of ozone depleted fragments of the vortex being advected to midlatitudes at times when the UV is high.

\subsection{Daily minimum ozone levels}

Daily minimum ozone levels south of $40^{\circ} \mathrm{S}$ have been calculated for each day from the assimilated total column ozone data base. A comparison of these values for 2000 to 2003 against the 1979 to 1999 climatology is presented in Fig. 13.

The minimum Antarctic ozone levels for the year 2000 to 2003 are generally close to the lower range of the 1979 to 1999 climatology up until the end of September. During November however, the values are more typical of the mean of the 1979 to 1999 climatology. As already reported by Alvarez-Madrigal et al. (2005), this suggests that minimum ozone levels over Antarctic in November are showing a more immediate return to pre-ozone hole values than the minimum values in September. When GOA GOME data are used in preference to Earth Probe TOMS data, minimum ozone values over the Antarctic in 2000 (where the differences are largest c.f. Fig. 11) are 20-40 DU lower than those shown in Fig. 13 but become very close to those shown in Fig. 13 by mid-August.

Annual minimum ozone levels south of $40^{\circ} \mathrm{S}$ together with the dates on which the minimum values occurred are plotted in Fig. 14.

While the annual minimum Antarctic total column ozone levels over recent years appear to show an up turn, the date on which the annual minimum occurs appears to continue moving earlier into the year over the whole analysis period.

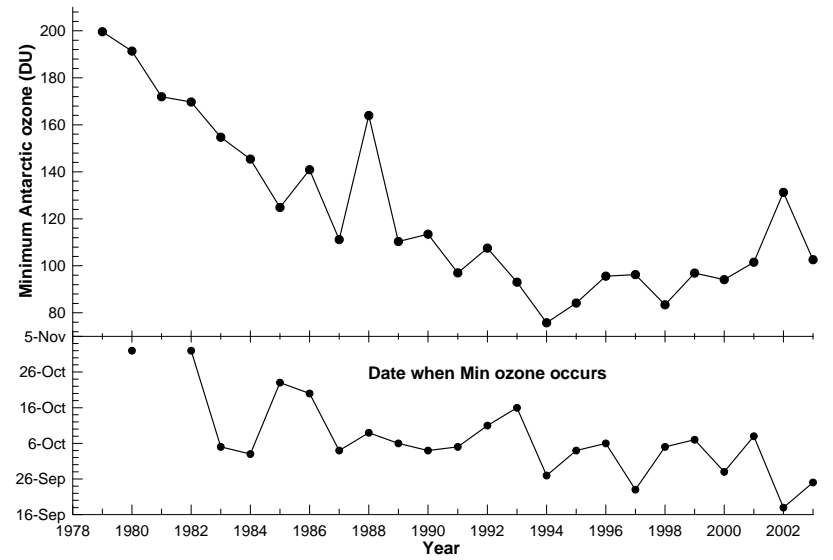

Fig. 14. Annual minimum Antarctic total column ozone levels and the date on which these minimum values occurred.

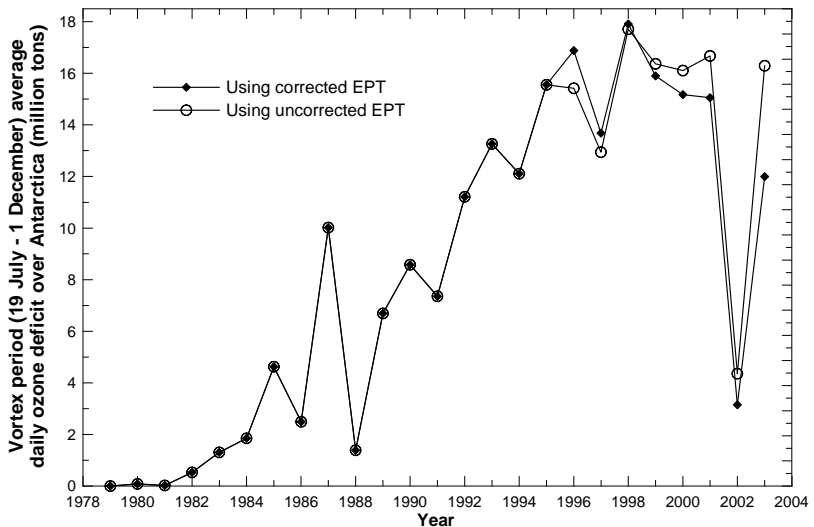

Fig. 15. The AVP mean ozone mass deficit $\left(\mathrm{O}_{3}<220 \mathrm{DU}\right)$ for each year in $10^{9} \mathrm{~kg}$. Values derived using the EPT data corrected after comparison with Dobson spectrophotometer measurements are shown using diamonds, while values derived using uncorrected EPT data are shown using circles.

The results are unaffected by the relative priority of the EPT and GOA data sets.

\subsection{Ozone mass deficit}

As in Bodeker and Scourfield (1995), the AVP mean ozone mass deficit has been calculated for each year and is plotted in Fig. 15.

The mass deficit provides a direct measure of the mass of ozone that would need to be added to the atmosphere to return ozone values over the Antarctic to above 220 DU and aids comparison with ozone changes over other parts of the globe (Uchino et al., 1999; Bodeker et al., 2001b). Clearly the application of the small corrections to the EPT data can change the conclusions that may be drawn from the ozone mass deficit data on recovery of the Antarctic ozone hole. Unlike the annual maximum area and the annual minimum 
total column ozone which show little change through the 1990s, the ozone mass deficit shows significant growth during the 1990s, almost doubling in value from $8.6 \times 10^{9} \mathrm{~kg}$ in 1990 to $15.2 \times 10^{9} \mathrm{~kg}$ in 2000 . This results from more severe depletion occurring close to the vortex edge (Bodeker et al., 2002; Newman et al., 2004) which changes the shape of the vortex (more bucket shaped rather than funnel shaped) without significantly changing the area of the ozone hole or the minimum values within the hole. Therefore, use of ozone hole area or minimum ozone values may not be the best metrics to gauge changes in the severity of the Antarctic ozone hole in recent years. These results are also unaffected by the relative priority of the EPT and GOA data sets.

\section{Conclusions}

A number of metrics describing the evolution of the Antarctic ozone hole over the period 1979 to 2003 have been developed. While some indicators such as the annual maximum ozone hole area and annual minimum ozone over the Antarctic show signs of saturation over the 1990s and the first few years of this century, the AVP mean ozone mass deficit shows large increases over the 1990s and clear signs of decreases over the period 1998 to 2003 (as long as the necessary corrections are applied to the Earth Probe TOMS data to account for their increasing drift with respect to the ground-based Dobson spectrophotometer network). This analysis therefore suggests that indicators such as the AVP mean ozone mass deficit, the annual date of disappearance of ozone hole values, or the November means of the Antarctic ozone hole area may be more suitable indicators for detecting the recovery of the Antarctic ozone hole than e.g. the annual maximum area of the hole or the annual minimum ozone values over the Antarctic. Whether or not they will ultimately be useful as indicators of Antarctic ozone hole recovery relies on the additional step of attributing the observed changes in the indicators to changes in ozone depleting substances. This is beyond the current scope of this paper. Many of the indicators derived above show a change in behaviour in the past 4 or 5 years. Whether or not this change is indicative of the onset of recovery in the Antarctic ozone hole is not yet clear and requires more detailed statistical investigation.

Acknowledgements. We would like to thank the Laboratory for Atmospheres at GSFC for access to SBUV and TOMS data, ESA/ESRIN for access to GOME data, NOAA for access to the SBUV data from the NOAA 9, NOAA 11 and NOAA 16 satellites, and Chi-Fan Shih at the National Center for Atmospheric Research and the National Centers for Environmental Prediction for the NCEP/NCAR data. We acknowledge Pieter Valks (DLR) who was involved in the development of TOGOMI, and Ronald van der A who processed the TOGOMI data set. We would also like to that the WOUDC for providing total column ozone measurements from the Dobson spectrophotometer network. This work was conducted within the FRST funded Drivers and Mitigation of Global Change programme (C01X0204).
Edited by: M. Dameris

\section{References}

Alvarez-Madrigal, M. and Pérez-Peraza, J.: Analysis of the evolution of the Antarctic ozone hole size, J. Geophys. Res., 110, D02107, doi:10.1029/2004JD004944, 2005.

Austin, J., Shindell, D., Beagley, S. R., Brühl, C., Dameris, M., Manzini, E., Nagashima, T., Newman, P., Pawson, S., Pitari, G., Rozanov, E., Schnadt, C., and Shepherd, T. G.: Uncertainties and assessments of chemistry-climate models of the stratosphere, Atmos. Chem. Phys., 3, 1-27, 2003,

SRef-ID: 1680-7324/acp/2003-3-1.

Bodeker, G. E. and Scourfield, M. W. J.: Planetary waves in total ozone and their relation to Antarctic ozone depletion, Geophys. Res. Lett., 22(21), 2949-2952, 1995.

Bodeker, G., Scott, J., Kreher, K., and McKenzie, R.: Global ozone trends in potential vorticity coordinates using TOMS and GOME intercompared against the Dobson network: 1978-1998, J. Geophys. Res., 106, 23 029-23 042, 2001 a.

Bodeker, G. E., Connor, B. J., Liley, J. B., and Matthews, W. A.: The global mass of ozone: 1978-1998, Geophys. Res. Lett., 28(14), 2819-2822, 2001b.

Bodeker, G. E., Struthers, H., and Connor, B. J.: Dynamical containment of Antarctic ozone depletion, Geophys. Res. Lett., 29(7), doi:10.1029/2001GL014206, 2002.

Daniel, J. S., Solomon, S., and Albritton, D. L.: On the evaluation of halocarbon radiative forcing and global warming potentials, J. Geophys. Res., 100(D1), 1271-1285, 1995.

Eskes, H. J.,van Velthoven, P. F. J., Valks, P. J. M., and Kelder, H. M.: Assimilation of GOME total ozone satellite observations in a three-dimensional tracer transport model, Q. J. R. Meteorol. Soc., 129, 1663-1681, 2003.

Fioletov, V. E., Bodeker, G. E., Miller, A. J., McPeters, R. D., and Stolarski, R.: Global and zonal total ozone variations estimated from ground-based and satellite measurements: 1964-2000, J. Geophys. Res., 107(D22), 4647, doi:4610.1029/2001JD001350, 2002.

Labow, G. J., McPeters, R. D., and Bhartia, P. K.: A comparison of TOMS \& SBUV version 8 total column ozone data with data from groundstations, in: Ozone, Proceedings of the XX Quadrennial Ozone Symposium, 1-8 June 2004, Kos, Greece, Vol. 1, edited by: Zerefos, C. S., pp. 123-124, International Ozone Commission, Athens, Greece, 2004.

McKenzie, R., Connor, B., and Bodeker, G.: Increased summertime $\mathrm{UV}$ radiation in New Zealand in response to ozone loss, Science, 285, 1709-1711, 1999.

McPeters, R. D., Bhartia, P. K., Krueger, A. J., Herman, J. R., Schlesinger, B. M., Wellemeyer, C. G., Seftor, C. J., Jaross, G., Taylor, S. L., Swissler, T., Torres, O., Labow, G., Byerly, W., and Cebula, R. P.: Nimbus-7 Total Ozone Mapping Spectrometer (TOMS) data products user's guide, NASA Ref. Publ. 1384, 1996.

Montzka, S., Butler, J., Myers, R. M. T., Swanson, T., Clarke, A., Lock, L., and Elkins, J.: Decline in the tropospheric abundance of halogen from halocarbons: implications for stratopsheric ozone depletion, Science, 272, 1318-1320, 1996.

Newman, P. A., Kawa, S. R., and Nash, E. R.: On the size of the Antarctic ozone hole, Geophys. Res. Lett., 31, L21104, 
doi:10.1029/2004GL020596, 2004.

Reinsel, G., Weatherhead, E. C., Tiao, G. C., Miller, A. J., Nagatani, R., Wuebbles, D. J., and Flynn, L. E.: On detection of turnaround and recovery in trend for ozone, J. Geophys. Res., 107(D10), doi:10.1029/2001JD000500, 2002.

Rinsland, C. P., Mahieu, E., Zander, R., Jones, N. B., Chipperfield, M. P., Goldman, A., Anderson, J., Russell III, J. M., Demoulin, P., Notholt, J., Toon, G. C., Blavier, J.-F., Sen, B., Sussmann, R., Wood, S. W., Meier, A., Griffith, D. W. T., Chiou, L. S., Murcray, F. J., Stephen, T. M., Hase, F., Mikuteit, S., Schulz, A., and Blumenstock, T.: Long-term trends of inorganic chlorine from ground-based infrared solar spectra: Past increases and evidence for stabilization, J. Geophys. Res., 108(D8), 4252, doi:4210.1029/2002JD003001, 2003.

Uchino, O., Bojkov, R., Balis, D.S., Akagi, K., Hayashi, M., and Kajihara, R.: Essential characteristics of the Antarctic-spring ozone decline: update to 1998, Geophys. Res. Lett., 26(10), 1377-1380, 1999.
Valks, P. and van Oss, R.: TOGOMI Algorithm Theoretical Basis Document, KNMI/ESA, 2003.

Veefkind, J. P. and de Haan, J. F.: OMI Algorithm Theoretical Basis Document, DOAS Total Ozone Algorithm, ATBD-OMI-02, Version 1.0, edited by: Bhartia, P. K., Vol. II, 2001.

Waugh, D. W., Randel, W. J., Pawson, S., Newman, P., and Nash, E. R.: Persistence of the lower stratospheric polar vortices, J. Geophys. Res., 104(D22), 27 191-27 201, 1999.

Wellemeyer, C. G., Bhartia, P. K., McPeters, R. D., Taylor, S. L., and Ahn, Ch.: A new release of data from the Total Ozone Mapping Spectrometer (TOMS), SPARC Newletter, 22, 37-38, SparcOffice, Service d' Aéronomie, Verrières-le-Buisson cedex, France, 2004, available at http://www.atmosp.physics.utoronto. $\mathrm{ca} / \mathrm{SPARC} /$.

WMO: Scientific Assessment of Ozone Depletion: 2002. Global Ozone Research and Monitoring Project, Report No. 47, World Meteorological Organization, Geneva, 498 pp, 2003. 